\title{
This time is different: Fiscal response to the COVID-19 pandemic among EU countries
}

B. Bökemeier M. Wolski 


\title{
This time is different: Fiscal response to the COVID-19 pandemic among EU countries
}

\author{
Bettina Bökemeier ${ }^{\mathrm{a}, *}$, Marcin Wolski ${ }^{\mathrm{b}, * *}$ \\ ${ }^{a}$ Bielefeld University \\ ${ }^{b}$ European Investment Bank
}

\begin{abstract}
This paper empirically analyses fiscal policy behavior in the European Union (EU) Member States and assesses how it has changed during the recent pandemic crisis compared to previous crisis situations. Based on panel estimations the outcomes reveal that this time is different, both concerning the policy direction as well as its magnitude. We confirm that fiscal policy has turned from formally pro-cyclical/a-cyclical design prior to COVID-19 period to countercyclical in the pandemic years. Moreover, this changeover is independent from the status of the EU membership, as it affects both Old Member States (OMS) and New Member States (NMS) likewise.
\end{abstract}

Keywords: COVID-19 pandemic, Discretionary Fiscal Policy, New Member States, Counter-Cyclical Policies, Fiscal Rules

JEL: E62, O52

\footnotetext{
${ }^{*}$ Corresponding author.

**Views presented in the paper are those of the authors only and do not necessarily represent the views of the European Investment Bank (EIB).

Email addresses: bboekemeier@wiwi.uni-bielefeld.de (Bettina Bökemeier), m.wolski@eib.org (Marcin Wolski)
} 


\section{Introduction}

The 2008 world financial crisis and the following debt crisis in Europe hit the affected economies across a spectrum of indicators, with declining growth rates, high unemployment and huge fiscal gaps, resulting in increasing public debt ratios. Economists, politicians and public opinion viewed that period as incisive with regard to fiscal policy and public finances, being often dubbed as "this time is different" (Reinhart \& Rogoff, 2009).

However, the recent COVID-19 pandemic and the associated economic downswing due to the health crisis is even more pronounced than before, making governments to take extraordinary actions to counter-steer and cushion its eco-

nomic impacts. Stringent containment measures, imposed to slow down the spread of the coronavirus (COVID-19 or C19), were quickly reflected in shortterm declines in economic activity and surges in public interventions across major economies (Gurría, 2020). The early data suggest that the pace and magnitude of the shock were unprecedented, as exemplified by business and consumer confidence indicators plummeting across the globe, with some subcomponents reaching all-time lows. Furthermore, March 2020 represented the month with the highest number of downgrades by rating agencies in the last twenty years. For example, as of the end of Q1 2020 Fitch Ratings put at negative outlook $83 \%$ of industry and structured finance assets, and all sovereign sector assets (Fitch Ratings, 2020).

Firms across regions have faced significant challenges from the worsening operating environment and economic shutdowns. While the quick rise in unemployment and jobless claims in major developed and emerging markets have been uneven across regions and sectors, fiscal balances have been put under pressure across the board. According to AMECO database, the share of public debt jumped from $78.8 \%$ of GDP in 2019 to $92.1 \%$ in 2021 in the EU. Furthermore, the government debt in the euro area reached the size of its economy for the first time in history. Without doubt, the fiscal response points to a clear counter-cyclical direction taken up by the policy makers across the EU. It re- 
mains unclear however, if the public debt levels increased solely to match the magnitude of economic contraction or if the fiscal reaction function has changed too.

In this context, the purpose of this study is threefold. Firstly, we put the recent fiscal reaction in historical perspective. In particular, we assess the degree of fiscal counter-cyclicality in the EU after the year 2000. We do that to better account for drawing on fiscal resources during the pandemic crisis and therefore, as we will argue later, support rationale why the European Commission suspended the Excessive Deficit Procecure (EDP) vis-a-vis the Member States in 2020. Secondly, we study the magnitude of the counter-cyclical behaviour throughout 2020 and 2021 in response to the economic contraction. In particular, we compare the previous instances in which the EDP was suspended and analyze if the pandemic years 2020 and 2021 were characterized by a significantly stronger counter-cyclical element. Thirdly, we analyze if fiscal reaction differs with respect to the EU status, i.e. between New Member States (NMS) versus Old Member States (OMS). ${ }^{1}$

We contribute to a substantial body of empirical literature, which studies the interaction of fiscal policy and the business cycle. Our particular focus is on discretionary policy, which we define as ad hoc policy deviations from predetermined rules and procedures present in the EU regulations. Many European Monetary Union (EMU) states appear to have followed pro-cyclical fiscal policies before 1992 and a-cyclical afterwards (Buti et al., 1997; Gali \& Perotti, 2003; Wyplosz, 2006). ${ }^{2}$ Von Hagen (2005) and Candelon et al. (2010)) argue that for several EMU states clear pro-cyclical patterns could have been observed even after 1992. The relation between fiscal rules and the business cycle seems

\footnotetext{
${ }^{1} \mathrm{NMS}$ refer to all EU countries which joined after 2004, including Croatia. Details are described in the data section below.

${ }^{2}$ The year 1992 marks the signature of the Maastricht Treaty, later followed by the Stability and Growth Pact (SGP) proposed in 1997, setting up a framework for sound and sustainable public finances in the EU. For more information about history of EU fiscal rules see Wyplosz (2006) or Fincke \& Wolski (2016).
} 
to vary, however, for the countries which joined the EU in the 21st century. For instance, based on the EU enlargement in 2004, Fincke \& Wolski (2016) find evidence that the adoption of EU fiscal rules might change public finance policy towards more counter-cyclicality. We take these observations as a starting point for this study, and assess how the recent pandemic situation might have challenged the conventional view that fiscal policy functions differ between OMS and NMS.

First, our results indicate that there is significant change in fiscal policy behavior from pro-cyclicality prior to the crisis to counter-cyclical behavior in the COVID-periods. Moreover, the estimations suggest that counter-cyclical fiscal policy could have been observed across the EU, independently on the membership status. Secondly, we demonstrate that, the same as the magnitude of the economic contraction, the degree of counter-cyclical behaviour throughout 2020 and 2021 was unprecedented. In particular, as we compare the previous periods in which the EDP was suspended, we show that the years 2020 and 2021 were characterized by a significantly stronger counter-cyclical element.

Bottom line, our results confirm the tragedy which the pandemic has brought onto the EU's economy. Unprecedented shocks require unprecedented measures, which is clearly visible not only in the change of the fiscal reaction function but also in its commonality across the EU. While we are far away from assessing the effectiveness of this approach, we believe we can draw from it several policy conclusions on the design of the EU fiscal rules.

In March 2020, the European Commission proposed for the first time the activation of the general escape clause that would pause the adjustments Member States have to do to meet their fiscal targets and allow them to spend freely. We confirm that this allowed the countries to act strongly against the cycle, cushioning the negative effects of the pandemic. If this counter-cyclical behaviour is any justification for temporarily relaxing the fiscal rules, the lesson from the pandemic crisis should be embedded in the regulatory framework. We believe that anchoring severe adverse scenarios explicitly in the EDP rules can make the regulation better fit-for-purpose, by bringing more certainty to the decision- 
making process and allowing for swift deployment of the necessary resources in a timely manner. However, the exact design of these rules, and whether they should include the after-crisis consolidation clauses, requires a more thorough assessment in the years after the pandemic.

The rest of the paper is organized as follows. Section 2 describes our data sources. Section 3 presents our empirical approach and displays the results, including several robustness checks. Section 4 summarizes the main findings and concludes the paper.

\section{Data}

Our primary data source is the AMECO (2020) database, which comprises annual data for $27 \mathrm{EU}$ countries and the UK over the years from 2000 until $2022 .^{3}$

We look at the Cyclically Adjusted Primary Balance (CAPB) and Output Gap (OGap), calculated in net terms as $\frac{Y_{t}-Y^{*}}{Y^{*}}$, i.e. the difference between the actual GDP $Y_{t}$ and the potential GDP $Y^{*}$ as percentage of potential GDP. These two variables serve as the main identification mechanism on the relationship between the central fiscal policy and the business cycle Fincke \& Wolski (2016). A positive coefficient signals counter-cyclical behavior (as fiscal policy would consolidate as the output increases), whereas a negative one reveals procyclical reactions (as fiscal policy would accelerate as output increases). Our control variables include also public debt and inflation, also taken from Ameco database. Public debt gives information on fiscal sustainability and inflation, as a monetary variable, captures the reaction of the financial markets and controls for monetary policy reaction. We create a time dummy $C 19$ for years 2020 and 2021 to study the effect of the pandemic.

To offer a credible benchmark for the pandemic situation, the following table lists all periods for the EU members over the past twenty years in which they

\footnotetext{
${ }^{3}$ The most recent observations should be understood as projections.
} 
underwent an Excessive Deficit Procedure (EDP). While during the heat of the financial and debt crisis in Europe, there were still some economies such as Luxembourg, Sweden or Estonia, that were not exposed to an EDP, in the recent pandemic situation all countries face severe fiscal difficulties and did not fulfill the criteria. Currently, the general escape clause is activated allowing countries to temporarily diverge from the possible fiscal consolidation requirements. ${ }^{4}$

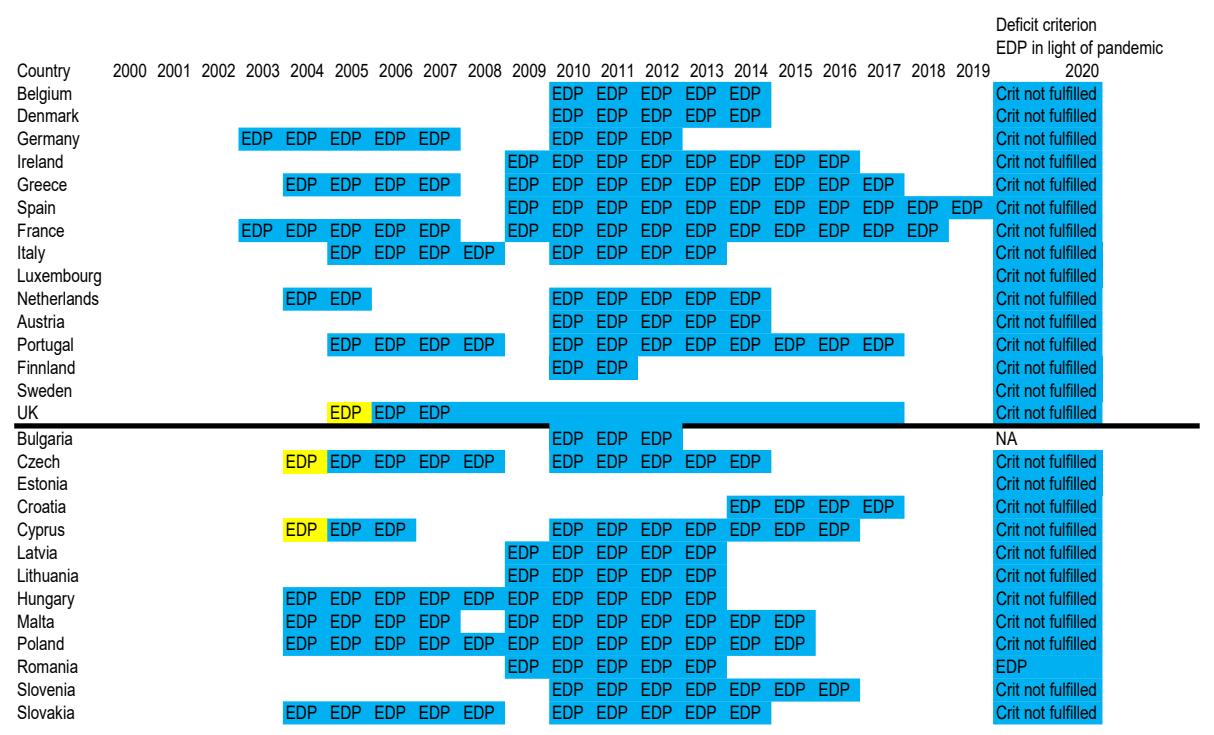

Figure 1: Overview on EDP in the selected economies. Sources: European Commission (2020) (blue), and Mathieu \& Sterdyniak (2005) p.14f. (yellow), own calculations.

\section{Results}

In view of the severity of the $\mathrm{C} 19$ pandemic situation we estimate the relationship between fiscal policy and the business cycle. We compare it to the previous crisis periods in Europe to see if there is empirical evidence to support that "this time is different". The estimation procedure starts with a simple

\footnotetext{
${ }^{4}$ The classification in categories is based on information on council decisions on the existence of an excessive deficit and abrogating that decision as published by European Commission (2020). See also Mathieu \& Sterdyniak (2005) Section 3 for details.
} 
fixed effects panel model. Eq. (1) outlines the main specification.

$$
\begin{aligned}
C A P B_{i, t} & =\beta_{0}+\beta_{1} C A P B_{i, t-1}+\beta_{2} C 19_{t} \times O G_{a p}, t \\
& +\beta_{3} C 19_{t}+\beta_{4} O G a p_{i, t}+\beta_{5} X_{i, t-1}+\mu_{i}+\varepsilon_{i, t}
\end{aligned}
$$

with $X_{i, t-1}$ as a vector of control variables, that is the debt to GDP ratio and inflation Inflation $_{t-1}$.

The results of the estimations of Eq. (1) on the full sample of years and countries are summarized in Table 1 . We also extend the model into several dimensions, testing its robustness. Column (1) presents the naked model from Eq. (1) without the control vector. Column (2) is our benchmark specification, including the controls. Column (3) interacts all controls with the COVID-19 pandemic dummy (those coefficients turned out to be insignificant and are not reported for transparency). The final column presents the dynamic panel results of Eq. (1), estimated with the Arellano-Bond estimator.

All specifications from Table 1 show that over the last years the EU Member States on average pursed pro-cyclical fiscal policies, as the coefficient OGap indicates a negative relation between the output gap and CAPB. Interestingly, this behavior entirely changes during the pandemic years. The interaction term $C 19 \times O G a p$ is significantly positive and exceeds the magnitude of the standalone coefficient, signalling a substantial shift to counter-cyclical behavior. The time dummy $C 19$ does not turn out to be significant.

Furthermore, there seems to be inertial behavior as the coefficient of the lagged primary balance $C A P B(\operatorname{lag})$ shows a significant positive value. This pattern is consistent across the model specifications (1-4) and it is also in line with previous studies (Fincke \& Wolski, 2016). Additionally high public debt appears to be reflected in subsequent fiscal consolidation, as indicated by the positive debt coefficient. The fiscal reaction seems to be unaffected by possible spillovers from the inflationary pressures, the for the majority of years the price levels were rather stable. Regarding the diagnostics, with 615 observations and based on an adjusted R-squared value ranging between 0.595 and 0.629 the 
Table 1: Fiscal rules in pandemic years.

\begin{tabular}{|c|c|c|c|c|}
\hline & (1) & (2) & (3) & $(4)$ \\
\hline & CAPB & CAPB & CAPB & CAPB \\
\hline \multirow[t]{2}{*}{ C19 × OGap } & $0.594^{* * *}$ & $0.519^{* * *}$ & $0.503^{* * *}$ & $0.601^{* * *}$ \\
\hline & $(0.095)$ & $(0.091)$ & $(0.092)$ & $(0.091)$ \\
\hline \multirow[t]{2}{*}{ OGap } & $-0.123^{* * *}$ & $-0.068^{*}$ & $-0.066^{*}$ & $-0.107^{* * *}$ \\
\hline & $(0.044)$ & $(0.034)$ & $(0.033)$ & $(0.031)$ \\
\hline \multirow[t]{2}{*}{ C19 } & -0.173 & $-0.853^{* *}$ & -0.343 & -0.086 \\
\hline & $(0.272)$ & $(0.321)$ & $(0.595)$ & $(0.307)$ \\
\hline \multirow[t]{2}{*}{ CAPB (lag) } & $0.592^{* * *}$ & $0.554^{* * *}$ & $0.552^{* * *}$ & $0.660^{* * *}$ \\
\hline & $(0.035)$ & $(0.035)$ & $(0.036)$ & $(0.033)$ \\
\hline \multirow[t]{2}{*}{ Debt (lag) } & & $0.037^{* * *}$ & $0.038^{* * *}$ & $0.007^{*}$ \\
\hline & & $(0.005)$ & $(0.006)$ & $(0.003)$ \\
\hline \multirow[t]{2}{*}{ Inflation (lag) } & & 0.028 & 0.031 & -0.020 \\
\hline & & $(0.044)$ & $(0.045)$ & $(0.031)$ \\
\hline \multirow[t]{2}{*}{ Constant } & $-0.099 * * *$ & $-2.287^{* * *}$ & $-2.370^{* * *}$ & -0.428 \\
\hline & $(0.023)$ & $(0.355)$ & $(0.374)$ & $(0.325)$ \\
\hline Observations & 615 & 615 & 615 & 615 \\
\hline R-squared & 0.595 & 0.629 & 0.629 & - \\
\hline Adj. R-squared & 0.574 & 0.608 & 0.607 & - \\
\hline Sargan p-val. & - & - & - & 0.033 \\
\hline
\end{tabular}

Notes: C19 is a time dummy for years 2020 and 2021. Column 1: (1) benchmark model without controls. Column 2: (2) benchmark model with controls. Column 3: benchmark model with all controls interacted with the C19 dummy (not reported as insignificant). Model 4: benchmark model with controls estimated using Arellano-Bond estimator. Coefficients are reported as well as country-clustered stangdard errors between brackets. *, **, and *** imply significance at the 10\%, 5\%, and 1\% significance level respectively. The adequacy of instrument space in Column 4 is tested with the Sargan test. 
model specifications present a reasonable fit. We also perceive the Sargan test results of over-identyfying restrictions to fall within an acceptable spectrum, given the data limitations and the sample size.

In the next step, we refine the model with respect to the EU status, that we provide the estimated on subsamples of OMS and NMS. This split of the sample allows to study whether the fiscal response in the one or the other group was different, as argued in the literature. Table 2 summarizes the results with the results for OMS given in Columns (1) and (2), and for the NMS in Columns (3) and (4).

While the results confirm the main findings from Table 1, they shed light on the differences between the Member States' fiscal reactions. Firstly, Columns (1) and (2), reveal that for the OMS the negative sign of the output gap coefficient points to a-cyclical behavior, understood as not statistically significant value. However, once the focus is on the C19 period (first row), the coefficients turn positive and significant indicating a switch towards counter-cyclical behavior.

Secondly, the results of the NMS in Columns (3) and (4) suggest this group conducted a statistically significant pro-cyclical fiscal policy, on average throughout the period. The interaction with the pandemic years shows a significant change to counter-cyclical fiscal policy, however. This changeover is even somewhat stronger in the NMS compared to the OMS. To sum up, we confirm that fiscal reaction function changed in the pandemic years to counter-cycylical status for both OMS and NMS. It seems that it is the pandemic situation that makes the difference but we run two further exercises to verify if similar patterns could have been observed in the past.

\subsection{What does the history tell us?}

We track the evolution of the fiscal policy by estimating the benchmark model on 3-year rolling window intervals. For transparency, the results are presented for $\beta_{1}$ coefficient for OMS and NMS separately in Figs. 2 and 3, respectively. 
Table 2: Fiscal rules in pandemic years between OMS and NMS.

\begin{tabular}{|c|c|c|c|c|}
\hline & (1) & $(2)$ & (3) & (4) \\
\hline & \multicolumn{2}{|c|}{ Old Member States } & \multicolumn{2}{|c|}{ New Member States } \\
\hline & CAPB & CAPB & CAPB & CAPB \\
\hline \multirow[t]{2}{*}{ C19 × OGap } & $0.519^{* * *}$ & $0.484^{* * *}$ & $0.868^{* * *}$ & $0.571^{* * *}$ \\
\hline & $(0.163)$ & $(0.138)$ & $(0.140)$ & $(0.145)$ \\
\hline \multirow[t]{2}{*}{ OGap } & -0.084 & -0.037 & $-0.155^{* * *}$ & $-0.092^{*}$ \\
\hline & $(0.101)$ & $(0.070)$ & $(0.038)$ & $(0.049)$ \\
\hline \multirow[t]{2}{*}{ C19 } & 0.031 & -0.664 & -0.070 & $-1.496^{* *}$ \\
\hline & $(0.464)$ & $(0.461)$ & $(0.401)$ & $(0.573)$ \\
\hline \multirow[t]{2}{*}{ CAPB (lag) } & $0.629^{* * *}$ & $0.595^{* * *}$ & $0.528 * * *$ & $0.415^{* * *}$ \\
\hline & $(0.051)$ & $(0.060)$ & $(0.058)$ & $(0.061)$ \\
\hline \multirow[t]{2}{*}{ Debt (lag) } & & $0.040^{* * *}$ & & $0.055^{* * *}$ \\
\hline & & $(0.011)$ & & $(0.007)$ \\
\hline \multirow[t]{3}{*}{ Inflation (lag) } & & 0.311 & & 0.014 \\
\hline & & 0.286 & & 0.011 \\
\hline & & $(0.300)$ & & $(0.021)$ \\
\hline \multirow[t]{2}{*}{ Constant } & 0.089 & $-3.185^{* *}$ & $-0.364^{* * *}$ & $-2.877^{* * *}$ \\
\hline & $(0.093)$ & $(1.236)$ & $(0.043)$ & $(0.311)$ \\
\hline Observations & 330 & 330 & 330 & 330 \\
\hline R-squared & 0.600 & 0.637 & 0.536 & 0.600 \\
\hline Adjusted R-squared & 0.576 & 0.614 & 0.508 & 0.573 \\
\hline
\end{tabular}

Notes: C19 is a time dummy for years 2020 and 2021. Columns 2 and 3: benchmark model without and with controls for Old Member States (OMS). Column 3 and 4: benchmark model without and with controls for New Member States (NMS). Coefficients are reported as well as country-clustered standard errors between brackets. *, **, and *** imply significance at the $10 \%, 5 \%$, and $1 \%$ significance level respeqtigely. 


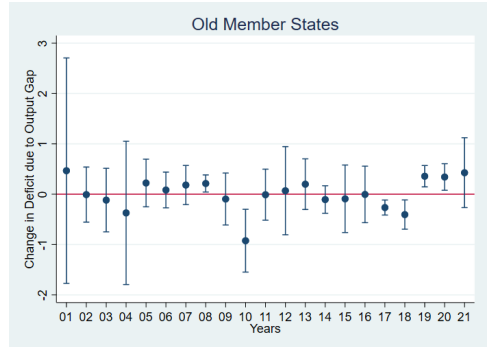

Figure 2: Coefficient plot for OMS.

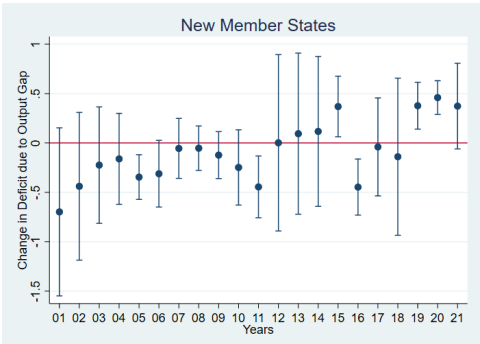

Figure 3: Coefficient plot for NMS.

The results indicate an alternating behavior over time, with patterns shifting for both groups over time. However, one characteristic clearly stands out. For the current period of the pandemic there is sustained change in fiscal behavior. The reaction of the budget variable is significantly positive for the years starting with 2018-2020 period for both country groups, indicating a change towards a counter-cyclical fiscal policy in face of the COVID crisis.

As a final step, we compare compare the current situation to the previous EDP periods. In particular, we estimate the benchmark model conditional on whether a country was under the EDP procedure as reported in Fig. 1. The results are presented in Figs. 4 and 5 for the two groups of countries.
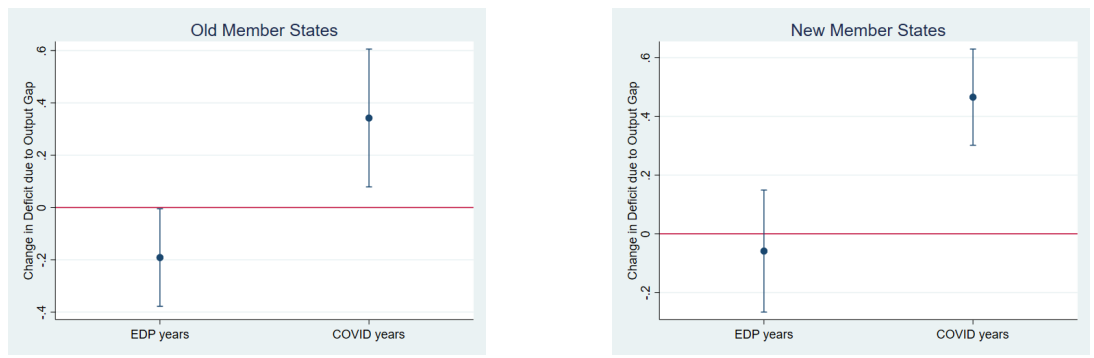

Figure 4: Coefficient comparison for OMS. Figure 5: Coefficient comparison for NMS.

The results indicate that the previous EDP periods were actually marked by rather pro-cyclical/a-cyclical fiscal policies across the Member States. There is, however, a distinctive change towards counter-cyclicality with a positive value in both groups during the pandemic years. We view that as a confirmation that 
the recent crisis was followed by an unprecedented shift in fiscal policy across the EU. This time is different.

\section{Conclusions}

This paper empirically investigates fiscal policy in EU Member States since the year 2000 and particularly analyses if there is a change in fiscal behavior in the pandemic years compared to the previous crisis periods. Moreover, we study the heterogeneity of fiscal reaction function due to the EU membership status.

Our results clearly indicate that there is significant switch in fiscal policy. While there was pro-cyclical/a-cyclical behavior prior to the crisis, in the recent pandemic Member States turned drastically to counter-cyclical fiscal policies. Furthermore, the estimations indicate that this is not necessarily dependent on the membership status but rather due to the extraordinary situation of the pandemic, even though the switch effect of counter-cyclical behavior is a little stronger in the NMS compared to the OMS.

Overall, we can demonstrate that the degree of counter-cyclical behaviour throughout 2020 and 2021 was unprecedented compared to previous situations in which the EDP was suspended. Our results show that the years 2020 and 2021 were characterized by a significantly stronger counter-cyclical element than any earlier period under investigation. While it is still too early to claim whether it was right or wrong, we conclude that this time was really different.

As a policy conclusion, we suggest that anchoring the cyclical-patterns in the EDP decisions can bring an extra anchor for the regulation to be better fit-forpurpose. This becomes particularly important as the temporarily suspension of the deficit rules comes to an end and restoring them may call for reforms and adjustment.

As the economy emerges from the pandemic, and more data points become available, it seems only natural to further investigate the effectiveness of the fiscal rules in the face of severe adverse shocks on a spectrum of socio-economic 
indicators. Our study is only the first step in this direction whereby we confirm that in 2020 and 2021 policy makers in the EU could not much rely on previous experience when deciding on fiscal policy.

\section{References}

AMECO (2020). Macro-economic database of the European Commission's Directorate General for Economic and Financial Affairs, https://ec. europa.eu/info/business-economy-euro/indicators-statistics/ economic-databases/macro-economic-database-ameco/ ameco-database_en, last access: October 9th, 2021.

Buti, M., Franco, D., \& Ongena, H. (1997). Budgetary Policies during Recessions - Retrospective Application of the Stability and Growth Pact to the Post-War Period. European Economy - Economic Papers 121 Directorate General Economic and Monetary Affairs, European Commission.

Candelon, B., Muysken, J., \& Vermeulen, R. (2010). Fiscal policy and monetary integration in Europe: an update. Oxford Economic Papers, 62, 323-49.

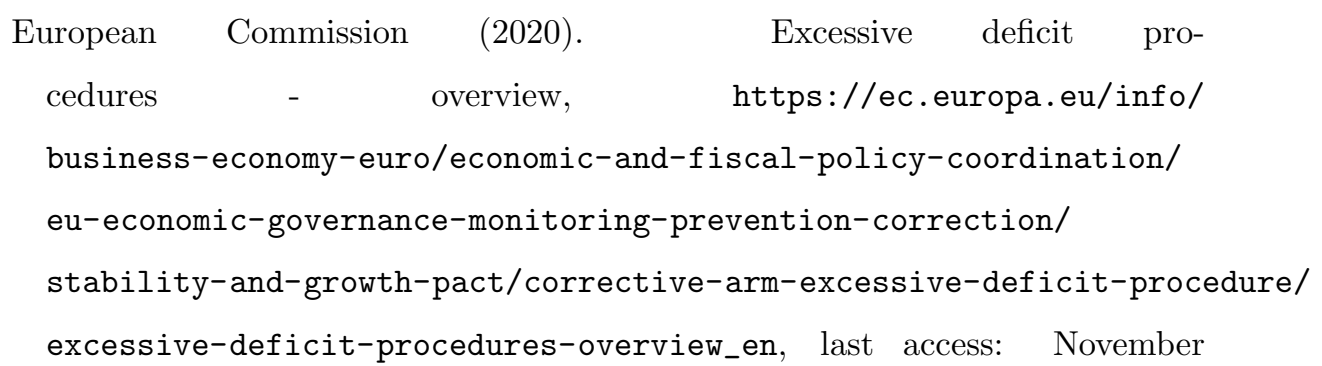

19th, 2020.

Fincke, B., \& Wolski, M. (2016). Are european fiscal rules that bad? Discretionary fiscal policies in new member states. Empirical Economics, 51, $517-546$.

$\begin{array}{rllcl}\text { Fitch } & \text { Ratings } & \text { (2020). } & \text { Fitch Ratings Updates } 2020 \text { Sec- } \\ \text { tor } & \text { Outlooks } & \text { To Reflect } & \text { Coronavirus Impact. } & \text { URL: https : }\end{array}$ 
//www.fitchratings.com/research/fund-asset-managers/

fitch-ratings-updates-2020-sector-outlooks-to-reflect-coronavirus-impact-27-03-2020.

Gali, J., \& Perotti, R. (2003). Fiscal policy and monetary integration in Europe.

Economic Policy, 18, 534-72.

Gurría, A. (2020). Statement for the G20 Videoconference Summit on COVID-19. URL: https://read.oecd-ilibrary.org/view/?ref=126_ 126445-5ofyod1xpv.

Mathieu, C., \& Sterdyniak, H. (2005). How to improve the european fiscal framework?, . http: // citeseerx. ist. psu. edu/viewdoc/download? do i=10. 1. 1. 540. 2595\&rep=rep1\& type $=p d f$, Last access: March, 15th, 2021.

Reinhart, C. M., \& Rogoff, K. S. (2009). This time is different: Eight centuries of financial folly. Princeton University Press.

Von Hagen, J. (2005). Fiscal rules and fiscal performance in the EU and Japan. IMES Discussion Paper, E-5, 1-29.

Wyplosz, C. (2006). European Monetary Union: The dark sides of a major success. Economic Policy, 21, 207-61. 